\title{
The Influence of Ageing on the Yield Strength and the Low-Temperature Strain Ageing Effect in Al-rich Al-Ag Alloys*
}

\author{
By Kôji Sumino**, Mikio Yamamoto** and Masae P. Sumino***
}

\begin{abstract}
With Al-Ag alloys containing $5 \sim 20 \mathrm{wt} . \% \mathrm{Ag}$, the time variation of the yield strength during ageing at various temperatures after quenching from $550^{\circ} \mathrm{C}$ and the effect of low-temperature strain ageing on the flow stress were studied. The yield strength was increased by $100^{\circ} \mathrm{C}$ aging. The amount of this increase has been found to be in reasonable agreement with the value calculated from X-ray data based on an idea of zone hardening proposed by Kelly. In connection with this, some discussions are made on the zone hardening. No increase of the flow stress was observed after strain ageing at room temperature and $100^{\circ} \mathrm{C}$. Short-time annealing at intermediate temperatures $\left(180^{\circ} \sim 200^{\circ} \mathrm{C}\right.$ ) caused a decrease in yield stress which may be due to a change in distribution or structure of the zones. The yield stress reveals the maximum value accompanied with the precipitation of the transient $\gamma^{l}$ phase and then decreases as the $\gamma^{l}$ precipitates grow larger. This can be interpreted as being associated with the variation of the stress-field around the precipitates during their growth. It is suggested that there may be a possibility of the nucleation of the $\gamma^{\prime}$ phase in the zones which will he promoted when there are some dislocation lines crossing the zones.
\end{abstract}

(Received April 6, 1962)

\section{Introduction}

The age-hardening effect in precipitation-type alloys is commonly utilized in industry and therefore it is important industrially. This phenomenon can be interpreted as the variation in deformability due to the precipitation of the second phase, but it is well known that the effect depends upon complicated and delicate factors. Since the plastic deformability of a crystalline substance is determined by the behavior of dislocations, the mechanism of the age-hardening effect is also thought to be interpreted eventually by the behavior of dislocations as affected by the transformation of the crystal structure. In fact, some dislocation-theoretical explanations have previously been reported about this effect ${ }^{(1)}$, but they have not yet been so elaborated as to describe completely diverse aspects of the effect. In order to clarify this complicated phenomenon, it is important to study the phenomenon systematically by picking out the determining factors one by one.

The authors have a plan of investigations to clarify the dynamical and statical interactions between the transformation of the crystal structure and the dislocations by measuring variations of the plastic properties due to the nucleation and growth of a new phase or a transition phase in alloys. The present study, as a first part of the planned series of investigations, deals with Al-rich $\mathrm{Al}-\mathrm{Ag}$ alloys as the prototype of alloys in which the elastic interaction between dislocations and solute atoms is thought to be exceptionally weak. Since $\mathrm{Al}-\mathrm{Ag}$ alloys show

* This paper was published in Japanese language in the Journal of the Japan Institute of Metals, 25 (1961), 410.

** The Research Institute for Iron, Steel and Other Metals, Tohoku University, Sendai, Japan.

*** Now at the Applied Science Laboratory, Faculty of Engineering, Tohoku University, Sendai, Japan.

(1) A. H. Cottrell : Dislocations and Plastic Flow in Crystals, Oxford Press, (1953), p. 125. phenomena such as the formation of zones and of a transition phase coherent to the parent phase, which are controlled mainly by the chemical binding between constitutent atoms, some information about the interaction between dislocations and reactions occurring in alloys may be obtained.

The phase diagram of the Al-Ag alloy system is shown in Fig. $1^{(2)}$. The objects of the present study are phenomena associated with the precipitation of

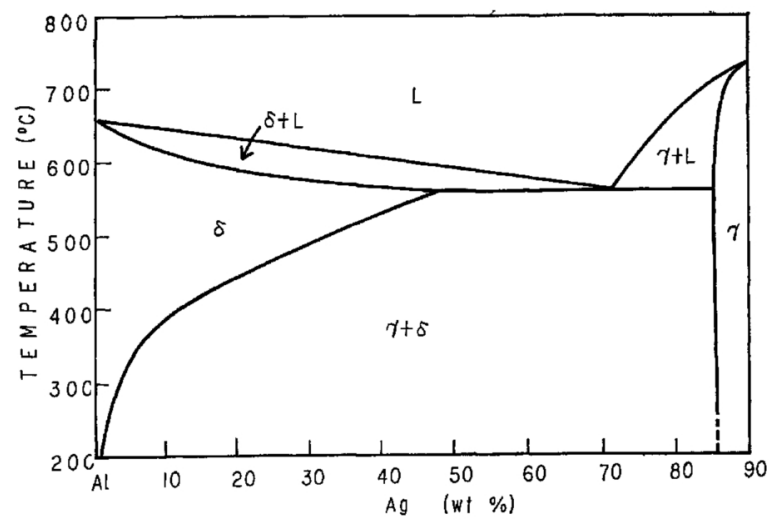

Fig. $1 \mathrm{Al}$-rich portion of the phase diagram of $\mathrm{Al}-\mathrm{Ag}$ alloys. (after Metals Handbook, ASM (1948))

the $\gamma$ (h.c.p.) phase from the supersaturated $\delta$ (f.c.c.) solid solution. It has already been established ${ }^{(3) \sim(5)}$ that, in this precipitation process, a transition phase $\left(\gamma^{\prime}\right)$ appears at a relatively early stage and thereafter the $\gamma$ phase grows. The $\gamma^{\prime}$ phase has the same lattice structure as, but has lattice parameters different from, the $r$ phase, being characterized by the fact

(2) Melals Handbook, ASM (1948).

(3) C. S. Barrett and A. H. Geisler : J. Appl. Phys., 11 (1940), 733.

(4) C. S. Barrett, A. H. Geisler and R. F. Mehl : Trans. AIME, $143(1941), 134$.

(5) A. H. Geisler, C. S. Barrett and R. F. Mehl : Trans. ATME, $152(1943), 182$. 
that the atomic distance in the basal plane is equal to that in the (111) plane of the matrix $\delta$ phase.

Further, a notable fact in connection with the precipitation in $\mathrm{Al}-\mathrm{Ag}$ alloys is the occurrence of zones which is especially remarkable after annealing at temperatures below $180^{\circ} \mathrm{C}^{(6)}$. It is considered that a silver-rich nucleus, which already existed in solid solution in equilibrium at a higher temperature, absorbs neighboring silver atoms and grows into a spherical zone composed of a spherical silver-rich core and a concentric silver-poor shell on the way of quenching or during aging at a lower temperature after quenching ${ }^{(7)(8)}$. After Guinier and his collaborators ${ }^{(6)(7)}$, the diameters of the silver-rich core and of the surrounding silver-poor shell as 16 and $72 \AA$, respectively, in the quenched state and they may grow to approximately twice the initial size after aging at lower temperatures. The zones have the same facecentered cubic structure as, and perfect coherence with, the matrix, there being no distinct boundary between them. Moreover, since the diameter of aluminum atom almost equals that of silver atom, the zones may not be accompanied by any appreciable strain field. Above about $180^{\circ} \mathrm{C}$, the zones are unstable and many silver atoms in the zones dissolve into the matrix after annealing for a short period of time, and the $\gamma^{\prime}$ phase and then the $\gamma$ phase precipitate independently of the zones ${ }^{(9)(10)}$. The origin of the zones and their correlation with precipitation phenomena have not yet been clarified. But, it seems reasonable, at present, to consider that the zone formation is not connected directly with precipitation phenomena.

The above-mentioned is an interpretation of the nature of the zones, based on studies hy Guinier and his collaborators ${ }^{(6)(7)}$. In contrast to this, Köster $e t$ al.(11)(12) observed with $38 \mathrm{wt} . \% \mathrm{Ag}$ alloy that something like a stacking fault appeared when a quenched supersaturated $\delta$ solid solution was annealed at a low temperature and that, during the reversion treatment (heating at a moderate temperature for a short time), it did not dissolve but grew into the $\gamma^{\prime}$ phase.

Although, at present, the view of Guinier and his collaborators seems dominant as far as the nature of the zones is concerned, that of Köster et al. starting from a stacking-fault like structure is also interesting in relation to the formation of precipitate nuclei at low temperatures, even if its correspondence with the nature of the zones is still in question.

It is to be noted that recently Nicholson and Nutting(13) have found, 16 wt.\% Ag alloy, using the

(6) C. B. Walker and A. Guimier: Compt. rend., 234 (1952), 2379.

(7) C. B. Walker, J. Blin and A. Guinier : Compt. rend., 235 (1952), 254.

(8) P. S. Rudman, P. A. Flinn and B. L. Averbach : J. Appl. Phys., 24 (1953), 365.

(9) B. Belbeoch and A. Guinier: Acta Met., 3 (1955), 370.

(10) V. Gerold : Z. Metallkde., 49 (1955), 623.

(11) G. Ziegler : Z. Metallkde., 43 (1952), 213.

(12) R. Glocker, W. Köster, J. Scherb and G. Ziegler : Z. Metallkde., 43 (1952), 208.

(13) R. B. Nicholson and J. Nutting : Acta Met., 9 (1951), 332. transmission electron microscopy, that the zones coexist with $\gamma^{\prime}$ precipitates and that the fringe contrast resulting from the $\gamma^{\prime}$ phase in an early stage of precipitation is the same as that coming from several overlapping stacking faults in the matrix.

\section{Specimens and Experimental Procedure}

An attempt was made first to prepare single crystal specimens of Al-Ag alloys using the Bridgeman method, but it was found difficult to obtain single crystals of uniform compsition on account of the great difference in density between aluminium and silver and the characteristic of the liquidus line in the phase diagram of this alloy system (see Fig. 1). Therefore, polycrystalline specimens were used in the present investigation. Ingots of Al-Ag alloys containing about 5, 10, 15 and 20 wt. $\% \mathrm{Ag}$ were prepared as follows :- Small pieces of $99.9 \%$ silver were added to $99.99 \%$ molten aluminum in an alumina crucible in an electric furnace. The melt was thoroughly mixed and then solidified rapidly to prevent the segregation. The Al$\mathrm{Ag}$ alloy ingots were cold drawn into wires $1.8 \mathrm{~mm}$ in diameter and the wires were cut into lengths of 10 $\mathrm{cm}$ to be used as specimens.

After the specimens were annealed at $550^{\circ} \mathrm{C}$ for 24 hours in a vacuum and then subjected to $1 \%$ elongation, they were again heated at $550^{\circ} \mathrm{C}$ for 24 hours to promote the grain growth and homogenization of the silver concentration, and then air-cooled. The grain size of the specimens thus prepared is several hundred microns, and the concentrations of silver in the specimens were found to be 5.09, 10.03, 15.36 and 21.12 wt.\% by chemical analysis.*

The specimens were electropolished in Jaquet's solution (14) and then vacuum-sealed into silica tubes of $2 \mathrm{~mm}$ diameter. Then, they were heated at $550^{\circ} \mathrm{C}$ for $4 \sim 5$ hours and quenched into water at room temperature. It was confirmed by X-ray examination that such quenching brought no detectable precititation of the $\gamma^{\prime}$ or $\gamma$ phase. These quenched specimens were submitted to tensile measurements, after subjected to various heat-treatments described later and then electropolished.

Fig. 2 shows schematically the tensile testing machine used. The applied load was measured by reading, using a dial gauge, the bending of spring-steel plate inserted in to the pulling system, while the elongation of the specimen was measured by reading, using another dial gauge, the change in distance between the upper and lower grips. Gauge lengths of the specimens were taken as $5 \sim 7 \mathrm{~cm}$.

\section{Experimental Results}

\section{Variation of the yield stress during ageing at lower temperatures}

Variations of the yield stress, $\sigma$, relative to the as-quenched value, $\sigma_{0}$, as observed when the speci-

* Chemical analysis was made by the staff of the common chemical analysis laboratory of our Research Institute.

(14) P. A. Jaquet: Compt. rend., 204 (1937), 1232. 
mens were aged at $100^{\circ} \mathrm{C}$ after quenching (from $550^{\circ} \mathrm{C}$ ) are shown in Fig. 3. It is to be noted that sets of full circles, full triangles, and of full squares (and of open circles and of open squares) in this and

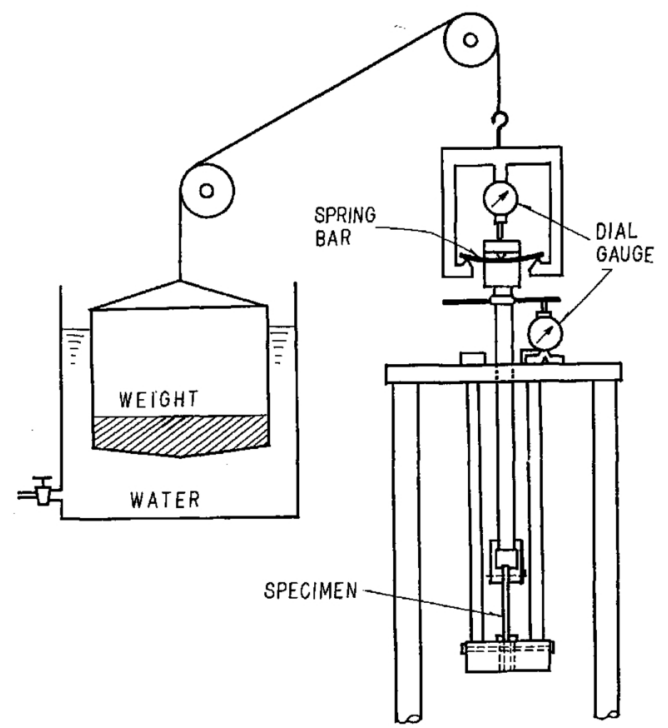

Fig. 2 Schematic diagram of the tensile apparatus used.

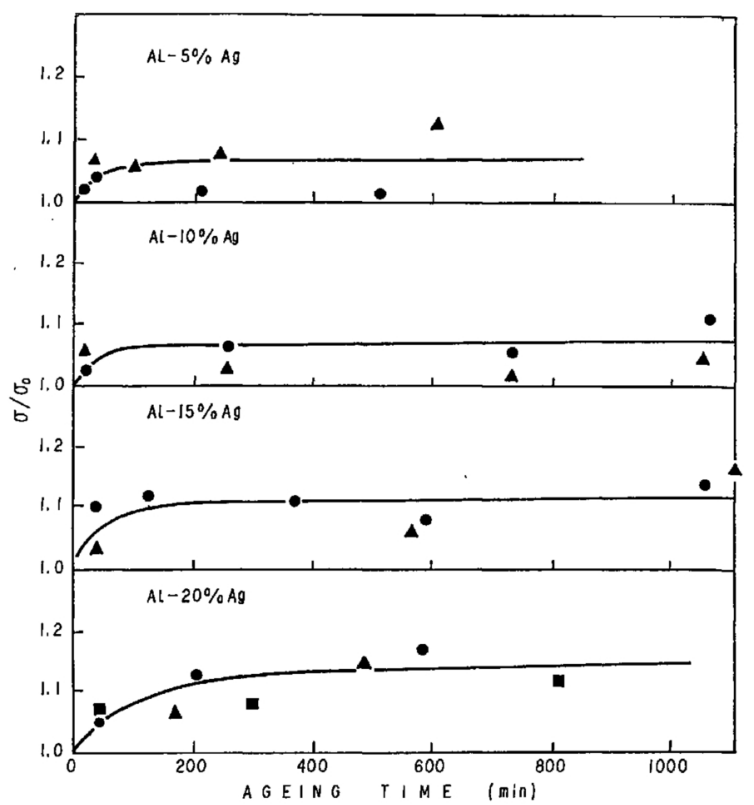

Fig. 3 Variation of the yield stress, $\sigma$, during ageing at $100^{\circ} \mathrm{C}$ in $\mathrm{Al}-\mathrm{Ag}$ alloys containing less than $20 \mathrm{wt} . \% \mathrm{Ag}$. $\sigma_{0}$ is the value of $\sigma$ in the quenched state.

succeeding figures represent the measured values on each one of the specimens. As seen from Fig. 3, the yield stress increases rapidly with increasing ageing time, attaining to saturation at an early ageing stage, and the increment of the yield stress by ageing is larger as the silver content is higher. During this ageing at $100^{\circ} \mathrm{C}, \mathrm{X}$-ray diffraction patterns did not show any trace of precipitation and no essential change in characteristics of the stress-strain curve could be detected.

It is to be noted that the measured data of the absolute values of the yield stress are scattered to a fairly large extent from specimen to specimen and that the yield stress of the specimen of which the surface was not sufficiently electropolished after quenching show a more complicated variation during ageing, which may probably be due to the surface strain introduced during quenching.

\section{Variation of the yield stress during ageing at intermediate temperatures}

Variations of the yield stress as observed when quenched $10 \% \mathrm{Ag}$ alloy specimens were aged at $180^{\circ} \mathrm{C}$ and when the quenched $15 \% \mathrm{Ag}$ alloy specimens were aged at $200^{\circ} \mathrm{C}$ are shown, respectively, in Figs. 4 (a) and (b). It can be seen from these figures

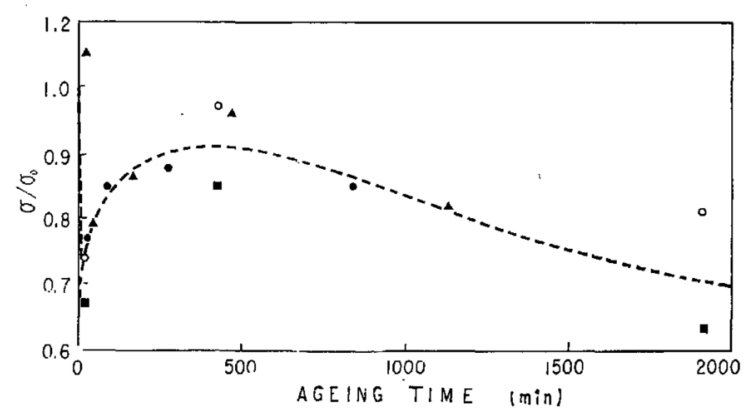

(a) $\mathrm{Al}-10 \% \mathrm{Ag}$ alloy, aged at $180^{\circ} \mathrm{C}$.

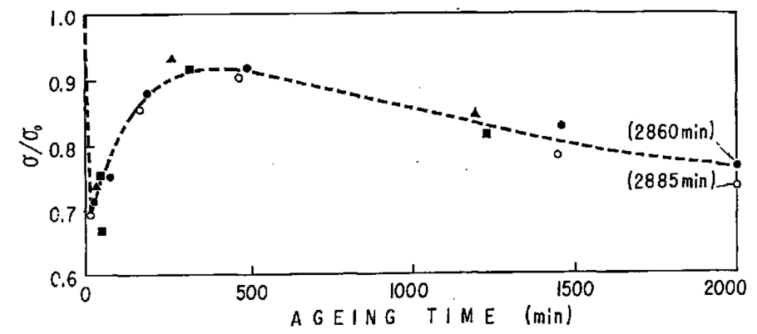

(b) $\mathrm{Al}-15 \% \mathrm{Ag}$ alloy, aged at $200^{\circ} \mathrm{C}$.

Fig. 4 Variation of the yield stress, $\sigma$ of $\mathrm{Al}-10 \% \mathrm{Ag}$ and $\mathrm{Al}-15 \% \mathrm{Ag}$ alloys during ageing at intermediate temperatures. $\quad \sigma_{0}$ is the value of $\sigma$ in the quenched state.

that the yield stresses of quenched $\mathrm{Al}-\mathrm{Ag}$ alloys aged at $180^{\circ} \mathrm{C}$ or $200^{\circ} \mathrm{C}$ fall in a short time to $65 \sim 70 \%$ of the as-quenched value, $\sigma_{0}$, but soon increase rapidly to maximum values lower than $\sigma_{0}$, and then decrease slowly again.

\section{Variation of the yield stress during ageing at higher temperatures}

Variations of the yield stress as observed when quenched 15 and $20 \% \mathrm{Ag}$ alloy specimens were aged at $250^{\circ} \mathrm{C}$ are shown in Figs. 5 (a) and (b), respectively. The measured points during aging at higher temperatures are scattered considerably as seen from these figures. But, as far as the same specmen is concerned, the measured data show a tendency expressed by broken lines in the figures, that is to say, the yield stress decreases more slowly with ageing time than in the case of ageing at intermediate temperatures (Fig. 4) and shows no definite maximum on the way of ageing. It is to be noted that fairly distinct $\mathrm{X}$-ray diffraction spots due to a hexagonal close-packed phase were observed after the quenched alloy specimens were aged at $250^{\circ} \mathrm{C}$ for 30 minutes.

\section{The effect of low temperature strain ageing on the flow stress}

The mechanism of the obstruction effect of solute 
atoms against the motion of dislocations can be clarified to a certain extent depending upon whether strain ageing effect occurs or not. The observational results on the effect of strain ageing at room temperature and at $100^{\circ} \mathrm{C}$ on the flow stress of $10 \% \mathrm{Ag}$ alloy

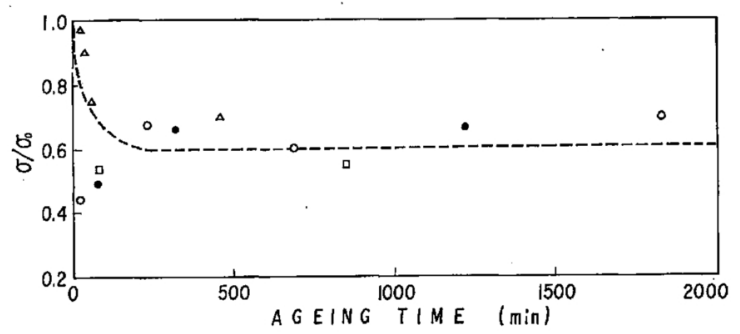

(a) $\mathrm{Al}-15 \% \mathrm{Ag}$ alloy

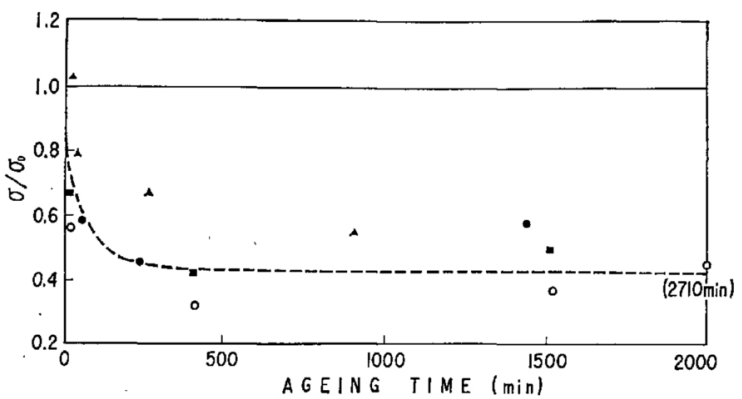

(b) $\mathrm{Al}-20 \% \mathrm{Ag}$ alloy

Fig. 5 Variation of yield stress, $\sigma$, of $\mathrm{Al}-15 \% \mathrm{Ag}$ and $\mathrm{Al}-20$ $\% \mathrm{Ag}$ alloys during ageing at $250^{\circ} \mathrm{C}$. $\sigma_{0}$ is the value of $\sigma$ in the quenched state.

specimens, which were aged beforehand at $100^{\circ} \mathrm{C}$ for $660 \mathrm{~min}$, namely, aged well at a lower temperature, are shown in Figs. 6 (a) and (b), respectively. Similar results were obtained on 15 and $20 \% \mathrm{Ag}$ alloy specimens, as shown in Figs. 7 and 8. As seen from these figures, only recovery occurs during low temperature strain ageing. This fact is in contrast with the case of $\mathrm{Al}-\mathrm{Cu}$ alloys ${ }^{(15)(16)}$ where the flow stress is increased by strain ageing, suggesting that the actions of copper atoms and silver atoms against the motion of dislocations are essentially different. This difference may be due to the fact that copper atoms can interact with dislocations in the isolated state but silver atoms can interact with dislocations only as an assembly.

\section{Discussions}

\section{Hardening due to the formation of the zones}

In the first place, we consider on the changes in mutual interaction between the zone and dislocation which may be expected to occur during the formation, growth, and disappearance of the zone. The changes in behavior of the dislocation during phase transition may generally be divided into the following two types:- the variation of its mobility and its mobility and its pinning down by a special arrangement of atoms. The former may be due to (a) the elastic stress field surrounding the new-phase particles or zones ${ }^{(17)}$, (b) the transformation of stable pairs

(15) K. M. Carlsen and R. W. K. Honeycombe : J. Inst. Metals, 83 (1955), 449.

(16) K. Matsuura and S. Kôda : Kinzoku Butsuri (Metal Physics), 4 (1958), 162 (in Japanese). of atoms to unstable ones by the passage of the dislocation (a short-range order hardening in a broad sense) ${ }^{(18)}$, and (c) the dispersion of the precipitated particles which do not permit the passage of dislocations ${ }^{(19)}$, while, the latter may come from (d) the

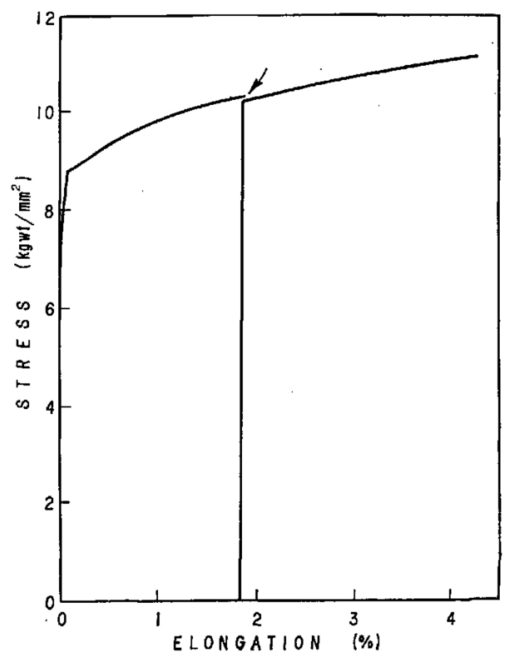

(a) Stain-aged at room temperature, and then at the arrow position, the specimen was unloaded, aged at the same temperature for 60 minutes and re-loaded.

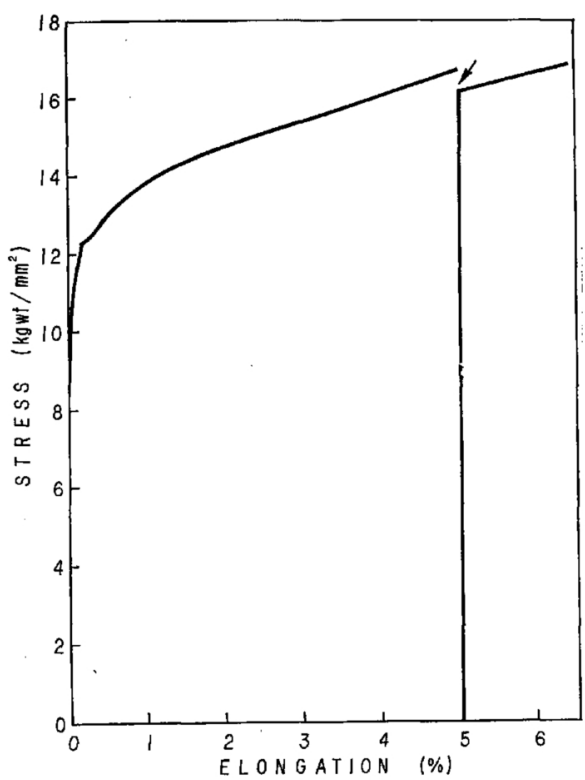

(b) Strain-aged at $100^{\circ} \mathrm{C}$, and then the specimen was unloaded, aged at the same temperature 4 minutes and re-loaded.

Fig. 6 Effect of strain-ageing at a lower temperature upon the stress-strain behavior at room temperature for $\mathrm{Al}-10 \% \mathrm{Ag}$ alloy aged beforehand at $100^{\circ} \mathrm{C}$ for 660 minutes.

elastic interaction between dislocations in the matrix and atomic arrangement in the zones or new-phase particles $(20)(21)$, (e) the chemical interaction between the new phase and stacking faults existing between the extended dislocations ${ }^{(22)}$, and (f) the electrical

(17) N. F. Mottt and F. R. N. Nabarro : Proc. Phys. Soc., 52 (1940), 86 .

(18) J. C. Fisher : Acta Met., 2 (1954), 9.

(19) J. C. Fisher, E. W. Hart and R.'H. Pry : Acta Met., 1 (1953), 336.

(20) A. H. Cottrell : Report of Strength of Solids, Phys. Soc. London (1948), p. 30.

(21) K. Sumino: Sci. Rep. RITU, A 10 (1958), 283.

(22) H. Suzuki : Sci. Rep. RITU, A 4 (1952), 455. 
interaction between dislocations and solute atoms ${ }^{(23)}$. However, it may only be the effect (b) that is mainly concerned with the formation and growth of the zones in Al-Ag alloys. In fact, it has been confirmed by $\mathrm{Jan}^{(24)}$, Ohta ${ }^{(25)}$ and Sato and Kelly ${ }^{(26)}$, using the

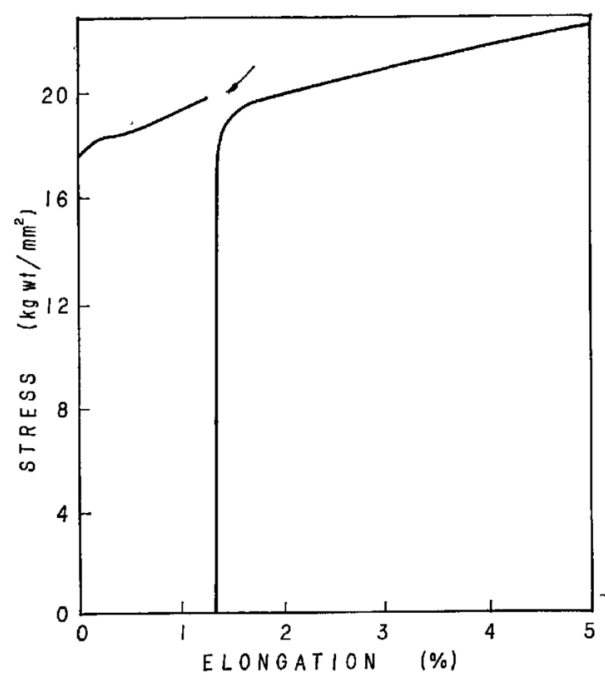

Fig. 7 Effect of strain-aging at $100^{\circ} \mathrm{C}$ hupon the stressstrain behavior at liquid nitrogen temperature of $\mathrm{Al}-15 \% \mathrm{Ag}$ alloy aged beforehand at $100^{\circ} \mathrm{C}$ for 625 minutes. An arrow indicates the point where specimen was unloaded, aged at $100^{\circ} \mathrm{C}$ for 325 minutes and re-loaded.

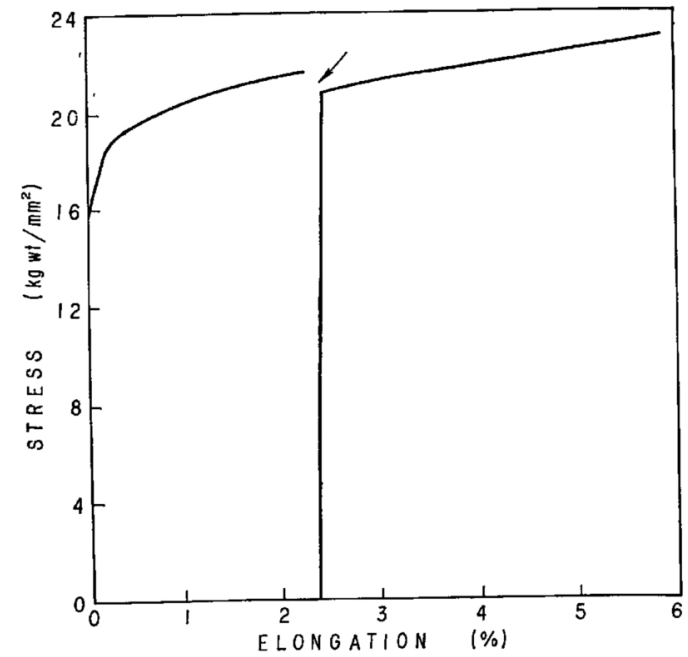

Fig. 8 Effect of strain-aging at $100^{\circ} \mathrm{C}$ upon the stress behavior at room temperature for $\mathrm{Al}-20 \% \mathrm{Ag}$ alloy aged beforehand at $100^{\circ} \mathrm{C}$ for 625 minuter. An arrow indicates the point where specimen was un loaded, aged at $100^{\circ} \mathrm{C}$ for 240 minutes and reloaded.

small-angle $\mathrm{X}$-ray scattering technique, that the zones in Al-Ag alloys are deformed by the passage of dislocations during plastic deformation.

Kelly et al.(27) have proposed, on the basis of effect (b), an idea of hardening due to the zones. If a certain ordered structure is assumed in a zone, the shear

(23) A. H. Cottrell, F، R. N. Nabarro and S. C. Hunter : 'Phil. Mag., A 4 (1953), 1064.

(24) J. P. Jan : J. Appl. Phys., 26 (1955), 1291.

(25) M. Ohta : Nippon Kinzoku Gakkai-shi (Journal of the Japan Instuite of Metals), 23 (1959), 177 (in Japanese).

(26) S. Sato and A. Kelly: Acta Met., 9 (1961), 59.

(27) A. Kelly and M. F. Fine: Acta Met., 5 (1957), 365 ; A. Kelly: Phil. Mag., 3 (1958), 1472. stress, $\sigma$, necessary to make a dislocation pass through the zone is given by

$$
\sigma=R \eta \mid \alpha b d,
$$

where $R$ is the average radius of the zones, $\eta$ the energy of the interface produced when a zone is passed through by the dislocation, $\alpha$ the shape factor, $b$ the Burgers vector of the dislocation, and $a$ the average distance between the centers of the zones. Kelly has calculated, from measured data ${ }^{(28)}$ on the heat of reversion of the alloy, an approximate value of $\eta$, which is equal to 150 ergs. $\mathrm{cm}^{-2}$. This value of $\eta$ leads to the value of $\sigma$ which is approximately equal to $7.0 \mathrm{~kg} / \mathrm{mm}^{2}$. Thus, if we assume that the initial decrease of the yield stress on ageing at intermediate temperatures (Fig. 4) is due to the dissolution of the zones existing just after quenching, its measured amount of about $4 \mathrm{~kg} / \mathrm{mm}^{2}$ may be reasonable.

With $38 \% \mathrm{Ag}$-Al alloy aged at various low temperatures, Belboech and Guinier ${ }^{(9)}$ determined the density of zones, $N$, and the number of silver atoms in a zone, $n$, using the samll-angle $\mathrm{X}$-ray scattering technique and assuming the concentration of silver atoms in the zones as 0.5 , and obtained the data shown in Table 1, of which the absolute values cannot be relied upon so much because of the inaccuracy insolved in the X-ray technique. As $R$ in Eq. (1) is proportional to $n^{1 / 3}$, the value of $n^{1 / 3} / d$ represents the

Table 1 Values of the density of the zones, $N$, and of the number of $\mathrm{Ag}$ atoms contained in each zone, $n$, in $\mathrm{Al}-38 \% \mathrm{Ag}$ alloy aged at various temperatures (Belbeoch and Guinier(9)). Values of $1 / d$ and $n^{1 / 3} / d$ are also given.

\begin{tabular}{c|c|c|c|c}
\hline \hline $\begin{array}{c}\text { Ageing temperature } \\
\left({ }^{\circ} \mathrm{C}\right)\end{array}$ & $\begin{array}{c}N \\
\left(10^{17} \mathrm{~cm}^{-3}\right)\end{array}$ & $n$ & $\begin{array}{c}1 / d \cdot \\
\left(10^{5} \mathrm{~cm}^{-1}\right)\end{array}$ & $\begin{array}{c}n^{1 / 3} / d \\
\left(10^{4} \mathrm{~cm}^{-1}\right)\end{array}$ \\
\hline After quenching & 2.4 & 2300 & 6.21 & 820 \\
130 & 3.4 & 3375 & 6.98 & 1047 \\
160 & 2.0 & 6600 & 5.85 & 1100 \\
175 & 0.4 & 11250 & 3.42 & 766 \\
\hline
\end{tabular}

relative magnitude of the flow stress of the zonehardened alloy. The values of $n^{1 / 3} / a$ estimated from the data of $N$ and $n$ are given in the last column of Table 1, from which it may be seen that the increase of the flow stress due to this cold-hardening is not more than $30 \%$ of the flow stress of the asquenched alloy being in good agreement with the results observed by us for the yield stress after ageing at $100^{\circ} \mathrm{C}$ (Fig. 3).

On the other hand, if a completely random arrangement of the atoms inside the zone is assumed, then the flow stress corresponding to Eq. (1) is expressed as

$$
\sigma=\eta^{\prime} \mid \beta d,
$$

where $\beta$ is again the shape factor and $\eta^{\prime}$ the energy of 'the' interface newly produced between the zone and matrix. If the above-mentioned value reported by Kelly for $\eta$ is substituted for $\eta^{\prime}, \mathrm{Eq}$. (2) gives a value of $\sigma$ which is too low to explain the magnitude of the cold-hardening. It must be noted, however, that Kelly's method is not very reliable for estimating

(28) W. Köster and M. A. Schell : Z. Metallkde., 43 (1952), 454. 
the value of $\eta$, the exact value of $\eta$ cannot be obtained without a detailed knowledge of the configuration of the atoms before and after the reversion treatment. According to Eq. (2), the flow stress or hardness of the alloy should vary as $1 / d$ during ageing at low temperatures. It is interesting to note that the temperature variation of $1 / d$ as derived from the data by Belbeoch and Guinier (9) (see Table 1) is quite similar to those of the hardness or the elastic limit obtained by Köster and Braumann(29), which is shown in Fig. 9. The positions of the maximum and minimum in the hardness-temperature curve coincide closely with

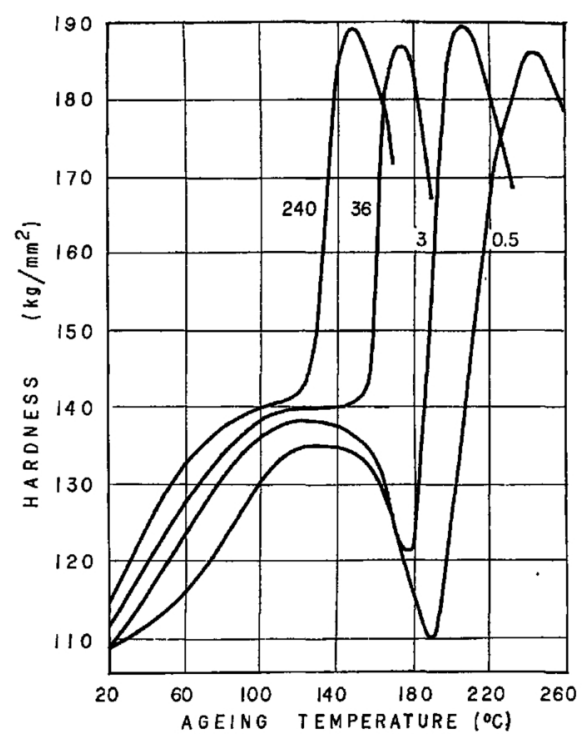

Fig. 9 Variation of the hardness with ageing temperature of $38 \% \mathrm{Ag}-\mathrm{Al}$ alloy. The ageing times expressed in hours are indicated on the curves (Köster and Braumann, (29))

those of the $1 / d$ temperatute curve, although there is a question regarding the absolute magnitude of the hardness or elastic limit.

\section{Relation between the zones and precipita-} tion of the new phase

Next, we discuss briefly the possible relation between the zones and precipitation of the new phase. It may be reasonable to consider that the configuration or structure of the zones are largely affected by the reversion treatment even though they do not disappear completely. But, it may be probable that a few zones, which accidently grew to a sufficiently large size, transform into very thin layers of the hexagonal closed-packed phase during low temperature ageing or reversion treatment. Such layers in an early stage of their growth may be considered as stacking faults in the matrix. The energy of the stacking fault in the Al-rich matrix is expected to be very high, but it may be very low in the zone-involving many silver atoms, because $\mathrm{AlAg}_{2}$ alloy is a close packed phase and the energy of the stacking fault in -pure silver is low as well. Such stacking faults involving high concentration of silver atoms possibly correspond to the stacking fault-like structures found by several authors (28)(30)(13), during low temperature ageing, although

(29) W. Köster and F. Braumann : Z. Metallkde., 43 (1952), 193.

(30) - Y. Fukano and S. Ogawa- J. Phys. Soc. Japan; 14-1959), 1671. some of them may be associated with dislocation loops introduced by quenching ${ }^{(13)}$.

Further, it is considered that such a stacking fault is very easily nucleated if a large zone is crossed by a dislocation, since the dislocation which is perfect in the matrix tends to extend in the zone and thus forms a belt-like stacking fault. It is not essential for the formation of this stacking fault that initially the zone is crossed by a dislocation, but if it is the case, the nucleation of the stacking fault may be very easy, although it is required that the zone concerned has a critical size which is determined by a balance between the line energy of the half dislocation and the energy of the stacking fault. This idea can account for the observational results obtained by Ohta(31). Ohta found, using the X-ray small-angle scattering technique, that the $\gamma^{\prime}$ phase precipitates very rapidly during $150^{\circ} \mathrm{C}$ ageing in the alloys containing welldeveloped zones when they were cold-worked prior to the ageing, while it precipitates less rapidly during $150^{\circ} \mathrm{C}$ ageing when the alloys were reverted prior to cold working. : In any case, the stacking fault formed in this way is surrounded by so many silver atoms that they may grow to a considerable size even at temperatures where the long-range diffusion of silver atoms does not take place and they also may grow rapidly by an enhanced diffusion of silver atoms along dislocations ${ }^{(32)}$. This new phase-like stacking fault may not dissolve on the reversion treatment but grow rapidly by collecting silver atoms and finally loses coherency with the matrix.

\section{The variation of yield stress due to the for- mation of the precipitate phase and its growth}

The measured results shown in Fig. 4 clearly suggest that the formation of the intermediate transition phase $\left(\gamma^{\prime}\right)$ results in an increase of the yield stress. The growth of this transition phase to a large size or into the equilibrium $\gamma$ phase is considered to be accompanied by a decrease of the yield stress, which accords with the experimental results of Köster et al (29) This may possibly be responsible for a relatively slow decrease of the yield stress in an early stage of ageing at $250^{\circ} \mathrm{C}$ (Fig. 5).

As the main cause of the hardening due to formation of the transition precipitate phase $\gamma^{\prime}$, the following may be enumerated:- (a) the stress field surrounding the $\gamma^{\prime}$ phase ${ }^{(33)},(b)$ the locking of dislocations by precipitation upon stacking faults accompanying them, and (c) the increase of the surface area of the $\gamma^{\prime}$ phase or the destruction of its structure owing to the passage of dislocations ${ }^{(13)}$. It is difficult to determine exactly which mechanism is predominatly responsible, unless the distribution of the $\gamma^{\prime}$ phase during ageing is accurately known. However, first of all, the mechanism (b) cannot interprete the decrease -in the yield stress

(31) M. Obta: Nippon Kinzoku Gakkai-shi (J. Japan Inst. of Metals), 23 (1959), 303 (in Japanese).

(32) R. E. Hoffman and D. Turnbull : J. Appl. Ṕhys., 22 (1951), 634.

(33) A:H. Geisler:Phase Trartsformations in Solidïs, John Wiley (1951), p. 387. 
accompanied by the growth of the $\gamma^{\prime}$ phase. In connection with the mechanism (a), Nicholson and Nutting ${ }^{(13)}$ found no coherent strain field around the precipitate at any stage of ageing in a thin foil specimen and attributed it to the accommodation of the misfit by the grid of partial dislocations at the periphery of the precipitate. It must be noted however, that the absence of the strain field around the $\gamma^{\prime}$ phase in the thin foil specimen does not necessarily mean its absence in the bulk crystal specimen, because the strain distribution in the thin foil specimen may be different from that in the bulk state and, moreover, the configurations of precipitates and of dislocations are only two dimensional in the thin foil specimen.

One possible explanation of the behaviour of the hardening due to the $\gamma^{\prime}$ precapitaion, which is based on the mechanism (a), may be as follows:- At the earliest stage of the precipitation, the $\gamma^{\prime}$ phase has perfect coherence with the matrix, but, as it grows larger, it gradually loses the coherence. In a certain thickness range, the precipitate may be stable if it keeps the coherence with a $\{111\}$ plane in the matrix, thus gaining in the chemical boundary energy but losing in the strain energy surrounding it which constitutes an obstacle against the motion of dislocations. This stage may correspond to the stage of the maximum hardening due to the $\gamma^{\prime}$ precipitation. When the ageing process proceeds further, the precipitation takes place in such a manner that the strain field is relieved due to the loss of coherency of the precipitate with the matrix and also due to the configuration of the precipitates that compensate the long-range stress field, thus resulting in a decrease in yield stress.

Another possible explanation based upon mechanism (c) was recently proposed by Nicholson and Nutting ${ }^{(13)}$. They claimed that the long-range order developed inside the $\gamma^{\prime}$ phase when it grew to a larger size and attributed the softening after prolonged ageing to the coarse dispersion of the $\gamma^{\prime}$ precipitates. Although this idea is quite interesting, it is needed for the complete explanation to establish the exact relationship between the size of the $\gamma^{\prime}$-precipitate (and hence the degree of order inside it) and its dispersion charateristics.

Finally, the behavior of the yield stress during ageing at hihger temperatures should be analysed in terms of the so-called dispersion-hardening.

\section{Summary and Conclusion}

The above-described experimental results and discussions may be summarized as follows :-

(1) An increase in yield stress was oberved when quenched $\mathrm{Al}-$ rich $\mathrm{Al}-\mathrm{Ag}$ alloys were aged at $100^{\circ} \mathrm{C}$. The amount of this increase is in reasonable agreement with the value calculated from Kelly's formula for the zone hardening as derived under the assumption of a certain ordered structure in the zone. The hardness (or elastic limit) vs. aging temperature behavior, however, can be explained more neatly by a formula for the zonehardening as derived under the assumption of the disordered structure of the zone.

(2) The strain-aging effect was not observed at room temperature or at $100^{\circ} \mathrm{C}$ with these alloys. This suggests that the mode of the interaction of silver atoms with dislocations in the Al-rich matrix is different from that of copper atoms.

(3) The yield stress in quenched Al-Ag alloys falls down on short-time annealing at intermediate temperatures $\left(180\right.$ to $\left.200^{\circ} \mathrm{C}\right)$. This may possibly be related to a change in distribution or structure of the zones.

(4) The intermediate transition phase $\left(\gamma^{\prime}\right)$ contributes to an increase of the yield stress during ageing of quenched Al-Ag alloys, and the growth of the $\gamma^{\prime}$ phase brings a decrease in the yield stress. These may be interpreted in terms of the changes, during the ageing process, in the strain field around precipitates, in shear resistance of precipitates, and in distribution of precipitates.

(5) The preferential nucleation of the $\gamma^{\prime}$ phase in the zone may be possible and it may be especially easy when a dislocation lies across the zone.

In closing, the authors express their hearty thanks to Prof. T. Suzuki for his helpful discussions and to Dr. M. Hirabayashi for giving us much facilities in connection with the $\mathrm{X}$-ray study. 